\title{
Inhibition of melanogenesis and antioxidant properties of Magnolia grandiflora L. flower extract
}

\author{
Huey-Chun Huang ${ }^{1}$, Wan-Yu Hsieh², Yu-Lin Niu ${ }^{3}$ and Tsong-Min Chang ${ }^{2 *}$
}

\begin{abstract}
Background: Magnolia grandiflora L. flower is wildly used in Asian as a traditional herbal medication. The purpose of the study was to investigate the antimelanogenic and antioxidant properties of Magnolia grandiflora L. flower extract. In the study, the inhibitory effects of M. grandiflora L. flower extract on mushroom tyrosinase, B16F10 intracellular tyrosinase activity and melanin content were determined spectrophotometrically. Meanwhile, the antioxidative capacity of the flower extract was also investigated.

Results: Our results revealed that M. grandiflora L. flower extract inhibit mushroom tyrosinase activity $\left(I C_{50}=11.1 \%\right.$; $\mathrm{V} / \mathrm{V})$, the flower extract also effectively suppressed intracellular tyrosinase activity $\left(I C_{50}=13.6 \%\right.$; $\left.\mathrm{V} / \mathrm{V}\right)$ and decreased the amount of melanin $\left(\mathrm{IC}_{50}=25.6 \% ; \mathrm{V} / \mathrm{V}\right)$ in a dose-dependent manner in B16F10 cells. Protein expression level of tyrosinase and tyrosinase-related protein 1 (TRP-1) were also decreased by the flower extract. Additionally, antioxidant capacities such as $\mathrm{ABTS}^{+}$free radical scavenging activity, reducing capacity and total phenolic content of the flower extract were increased in a dose-dependent pattern.

Conclusions: Our results concluded that M. grandiflora L. flower extract decreased the expression of tyrosinase and TRP-1, and then inhibited melanogenesis in B16F10 cells. The flower extract also show antioxidant capacities and depleted cellular reactive oxygen species (ROS). Hence, M. grandiflora L. flower extract could be applied as a type of dermatological whitening agent in skin care products.
\end{abstract}

Keywords: Magnolia grandiflora L, Melanogenesis, Tyrosinase, Melanin, Antioxidant

\section{Background}

Melanin plays an important role in protection the skin against ultraviolet light injury and is responsible for skin color. However, overproduction and accumulation of melanin result in several skin disorders including freckles, melasma, age spots and other hyperpigmentation syndrome [1]. Tyrosinase (monophenol, L-dihydroxyphenylalanine (L-DOPA): oxygen oxidoreductase EC 1.14.18.1) is the key enzyme in the first two steps of melanin biosynthesis, in which L-tyrosine is hydroxylated to L-DOPA (o-diphenol product), and L-DOPA is further oxidized into the corresponding o-quinone [2]. It has been reported that microphthalmia-associated transcriotion

\footnotetext{
* Correspondence: ctm@sunrise.hk.edu.tw

${ }^{2}$ Department of Applied Cosmetology \& Master Program of Cosmetic Science, Hung Kuang University, No. 34, Chung-Chie Rd., Shalu, Taichung City, Taiwan 43302

Full list of author information is available at the end of the article
}

factor (MITF) and other enzymes such as tyrosinase related protein-1 (TRP-1) and tyrosinase related protein-2 (TRP-2) also contribute to the production of melanin [3-5]. Recently, melanogenesis inhibitors have been increasingly applied in skin care cosmetics for the prevention of hyperpigmentation [6]. In addition, melanogenesis is reported to produce hydrogen peroxide $\left(\mathrm{H}_{2} \mathrm{O}_{2}\right)$ and other reactive oxygen species (ROS) which makes the melanocytes under high-grade oxidative stress. It is well known that ROS play a significant role in the regulation of the melanogenesis, while ROS scavengers and inhibitors of ROS generation may down-regulate UV-induced melanogenesis [7]. Therefore, antioxidants such as ascorbic derivatives and reduced glutathione (GSH) have been applied as inhibitory agents of melanogenesis $[8,9]$.

Magnolia grandiflora L. (Magnoliaceae) is widely used as a traditional medicine for the treatment of diarrhea, abdominal diseases, rheumatic arthritis, heart disturbances, 
high blood pressure, epilepsy, infertility and fever [10]. The aqueous extracts of flowers and leaves have been reported to exhibit cardiovascular effects [11] and was also used as an anticonvulsant in rat [12]. Chemical studies on $M$. grandiflora L. and other plants of the same genus, such as M. officinalis, have reported the presence of magnolol and honokiol [13,14], which exhibit muscle relaxant activity [15], inhibitory effects on skin tumour promotion [16] and antimicrobial properties [17]. It is interesting to find that M. grandiflora L. contains a number of sesquiterpene lactones which possess anti-inflammatory properties and used for treatment of pain [18]. A number of biologically active alkaloids [14], sesquiterpenes [19], phenolic constituents [17], glycosides [20] and other compounds [21] have been isolated from this species. However, scientific studies of the antimelanogenic and antioxidant properties of this medicinal plant are lacking.

The aim of this study was to investigate the inhibitory effects of $M$. grandiflora L. flower extracts on mushroom tyrosinase activity, murine intracellular tyrosinase activity, expression of melanogenesis-related proteins and melanin content in B16F10 melanoma cells, as well as its antioxidant activities.

\section{Results}

Effect of M. grandiflora L. flower extract on B16F10 cell viability

The MTT assay was used to assess the effect of $M$. grandiflora L. flower extract on B16F10 melanoma cells viability. The cells were treated with various concentrations of the flower extract $(10,12.5,15,17.5,20 \%$; v/v) for $24 \mathrm{~h}$ and then MTT assay was performed. Results are expressed as percent viability relative to control. After treatment, M. grandiflora L. flower extract show no cytotoxic effect on B16F10 cell proliferation (Figure 1).

\section{Effect of M. grandiflora L. flower extract on mushroom tyrosinase activity, B16F10 melanin content and intracellular tyrosinase activity}

In order to assay the inhibitory effect of the flower extract on mushroom tyrosinase activity, tyrosinase enzyme inhibition experiments were carried out in triplicate. The results indicated that mushroom tyrosinase activity was inhibited by the various concentrations of $M$. grandiflora L. flower extract. The remained tyrosinase activity was $48.14 \pm 7.92 \%, 41.32 \pm 5.90 \%$ and $38.75 \pm 8.5 \%$ of control for 10,15 and $20 \%(\mathrm{v} / \mathrm{v})$ of the flower extract, respectively. The $\mathrm{IC}_{50}$ of the flower extract on mushroom tyrosinase is $11.1 \%(\mathrm{v} / \mathrm{v})$. Meanwhile, mushroom tyrosinase activity was also inhibited by kojic acid $(200 \mu \mathrm{M})$ and remained enzyme activity was $29.21 \pm 3.12 \%$ of that of control (Figure 2A). Hence, M. grandiflora L. flower extract may act as a tyrosinase inhibitor.

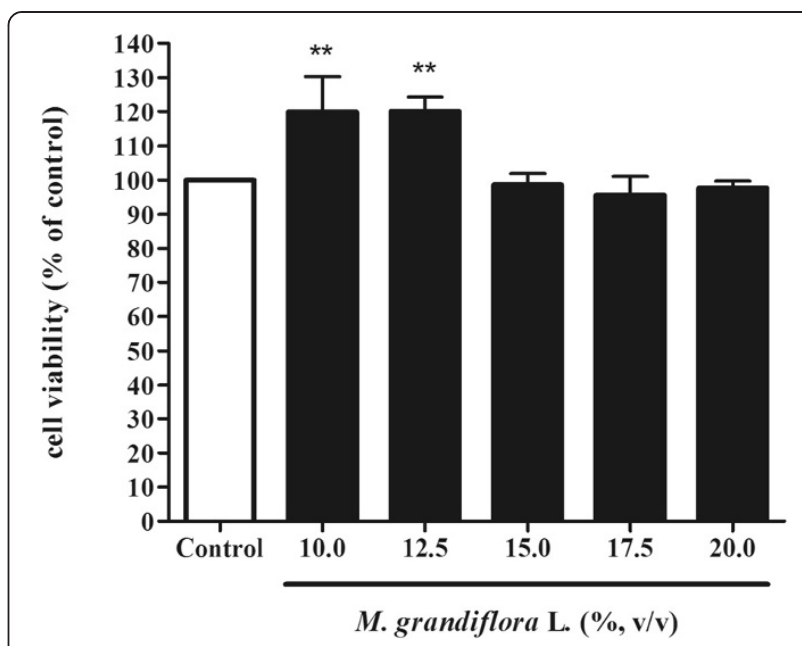

Figure 1 Effect of $M$. grandiflora L. flower extract on B16F10 cell viability. Cells were treated with various concentration of flower extract $(10,12.5,15,17.5,20 \%$; v/v) for $24 \mathrm{~h}$ and the cell viability was measured by MTT assay. Results are expressed as percentage of cell viability relative to control. Data are presented as mean \pm S.D. Values are significantly different by comparison with control. ${ }^{* *} p<0.01$.

To determine the antimelanogenic activity of $M$. grandiflora L. flower extract, the inhibitory effect of the flower extract on melanin content in B16F10 melanoma cells was assayed. B16F10 cells were first stimulated with $\alpha$-MSH $(100 \mathrm{nM})$ for $24 \mathrm{~h}$, and then cultured in the presence of the flower extract at 10, 15 and $20 \%(\mathrm{v} / \mathrm{v})$ or arbutin $(2.0 \mathrm{mM})$, respectively. Treatment with the flower extract showed a significant inhibitory effect on melanin synthesis in a dose-dependent pattern. The melanin content was represented as percentage of control. After treatment, the melanin content was $83.22 \pm 0.64 \%$, $70.49 \pm 2.23 \%$ and $62.48 \pm 2.10 \%$ for 10,15 and $20 \%(\mathrm{v} / \mathrm{v})$ of the flower extract, respectively (Figure $2 \mathrm{~B}$ ). The $\mathrm{IC}_{50}$ of the flower extract on B16F10 melanin content is 25.6\% (v/v). Meanwhile, B16F10 cells were treated with arbutin $(2.0 \mathrm{mM})$ as positive standard, and the remained intracellular melanin content was $73.34 \pm 1.00 \%$ of control for arbutin.

To examine the action mechanism of the inhibitory effect of M. grandiflora L. flower extract on melanogenesis more precisely, we assessed intracellular tyrosinase activity in B16F10 melanoma cells. The cells were first stimulated with $\alpha-\mathrm{MSH}(100 \mathrm{nM})$ for $24 \mathrm{~h}$, and then cultured with various concentrations of the flower extract $(10,15$, $20 \%$; v/v) or arbutin $(2.0 \mathrm{mM})$ for another $24 \mathrm{~h}$. The flower extract significantly inhibited $\alpha$-MSH-induced tyrosinase activity in a dose-dependent pattern. After these treatments, the remaining intracellular tyrosinase activity was $72.80 \pm 2.30 \%, 32.28 \pm 2.35 \%$ and $24.61 \pm 1.16 \%$ for 10 , 15 and $20 \%(\mathrm{v} / \mathrm{v})$ of the flower extract, respectively. The $\mathrm{IC}_{50}$ of the flower extract on B16F10 intracellular tyrosinase is $13.6 \%(\mathrm{v} / \mathrm{v})$. Meanwhile, the intracellular tyrosinase 


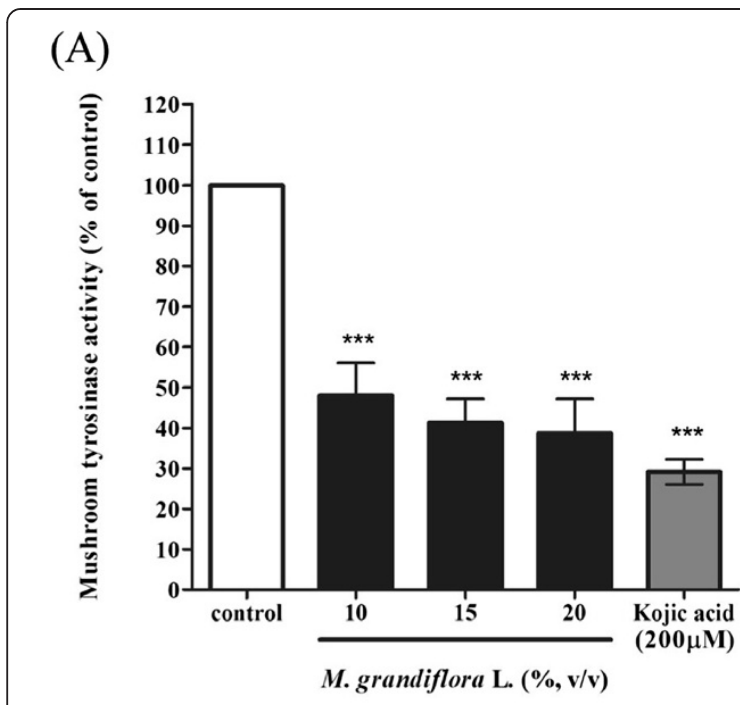

(B)

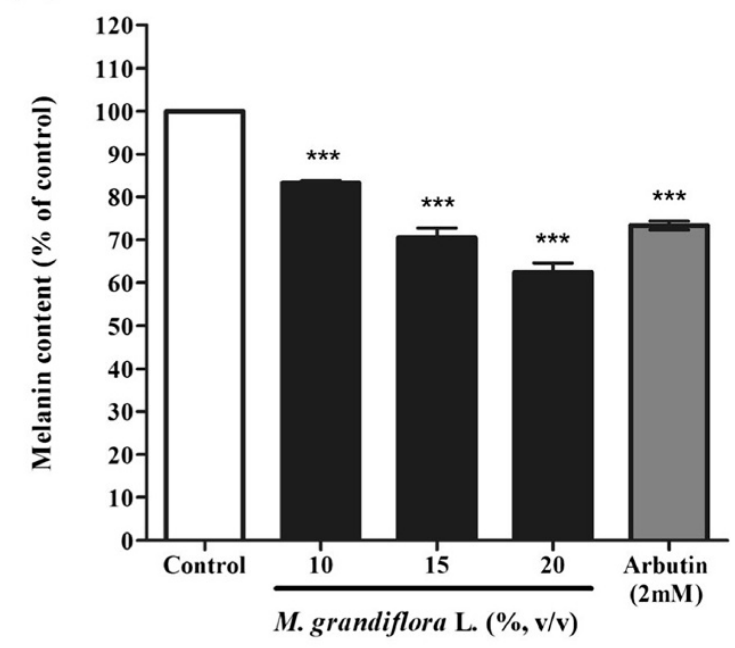

(C)

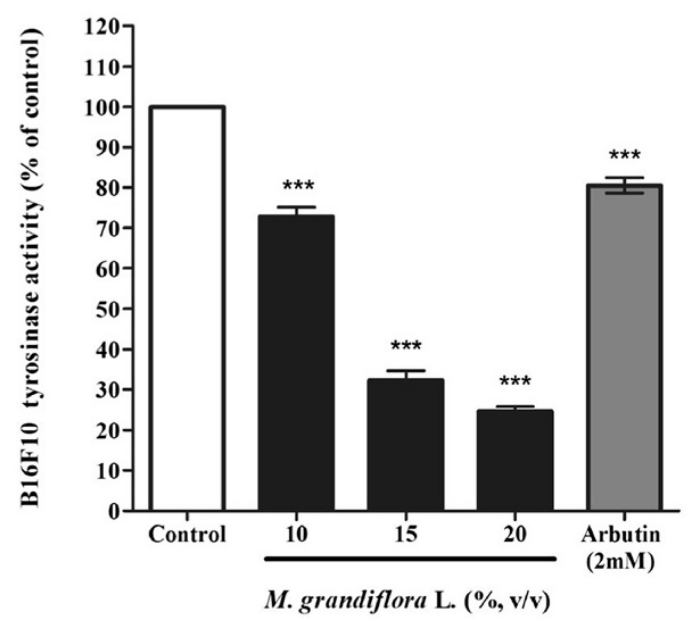

Figure 2 Inhibitory effect of $M$. grandiflora L. flower extract on mushroom tyrosinase activity, B16F10 melanin content and intracellular tyrosinase actvity. (A) Different concentrations of the flower extract (10, 15, 20\%; v/v) or kojic acid (200 $\mu \mathrm{M})$ was incubated with the same units of mushroom tyrosinase. Following incubation, the amount of dopachrome produced was determined at $490 \mathrm{~nm}$ spectrophotometrically. (B) \& (C) B16F10 melanoma cells were stimulated with a-MSH (100 nM) for $24 \mathrm{~h}$, and then the melanin content or intracellular tyrosinase activity were measured after treatment with various concentrations of the flower extract (final concentration 10, 15, 20\%; v/v) or arbutin (2.0 mM) for another $24 \mathrm{~h}$. Results are represented as percentages of control, and data are presented as mean \pm S.D. for three separate experiments. Values are significantly different by comparison with control. ${ }^{* *} p<0.001$.

activity was $80.55 \pm 1.91 \%$ after the cells were treated with arbutin $(2.0 \mathrm{mM})$ (Figure $2 \mathrm{C}$ ).

\section{Effect of M. grandiflora L. flower extract on expression of melanogenesis-related proteins}

To test whether $M$. grandiflora L. flower extract does regulate the expression of melanogenesis-related proteins, B16F10 melanoma cells were treated with $\alpha-\mathrm{MSH}$ (100 nM) for $24 \mathrm{~h}$, and then 10,15 , and $20 \%(\mathrm{v} / \mathrm{v})$ of $M$. grandiflora L. flower extract or kojic acid $(200 \mu \mathrm{M})$ was added for another $24 \mathrm{~h}$. MITF, tyrosinase, TRP-1, and TRP-2 levels were assayed by Western blot (Figure 3A). It was found that $M$. grandiflora L. flower extract treatment led to a reduced level of tyrosinase and TRP-1 (Figure 3B), but the protein contents of MITF and TRP-2 were not obviously changed after treatment (Figure 3A).

\section{Antioxidant capacities of $M$. grandiflora L. flower extract}

The $\mathrm{ABTS}^{+}$assay was first employed to measure the antioxidant activity of the flower extract of $M$. grandiflora L. Different concentrations of the flower extract (final concentration 10, 15, 20\%; v/v), Vitamin C $(50 \mu \mathrm{M})$, Vitamin E $(50 \mu \mathrm{M})$ or BHA $(0.1 \mathrm{mg} / \mathrm{ml})$ were incubated with $\mathrm{ABTS}^{+}$ solution, respectively. The $\mathrm{ABTS}^{+}$scavenging capacity of the flower extract was $22.15 \pm 1.07 \%, 29.06 \pm 1.73 \%$ and $32.49 \pm 1.92 \%$ of control for the flower extract at the concentration of 10,15 and $20 \%(\mathrm{v} / \mathrm{v})$, respectively. Meanwhile, the $\mathrm{ABTS}^{+}$scavenging capacity of Vitamin C, Vitamin E and BHA was 92.19 $\pm 0.28 \%, 60.13 \pm 2.48 \%$, $85.29 \pm 0.58 \%$, respectively. The results indicated that the flower extract of $M$. grandiflora L. scavenges $\mathrm{ABTS}^{+}$free radical significantly in a dose-dependent manner. However, the flower extract show lower $\mathrm{ABTS}^{+}$radical scavenging capacity than Vitamin $\mathrm{C}$, Vitamin $\mathrm{E}$ or BHA do (Figure 4A).

To determine the amount of total phenolic contents of $M$. grandiflora $L$. flower extract $(10,15,20 \%$; v/v), gallic acid $(2 \mu \mathrm{g} / \mathrm{ml})$ was used as positive standard. The results in Figure $4 \mathrm{~B}$ showed that the total phenolic contents in 10, 15 and $20 \%(\mathrm{v} / \mathrm{v})$ of M. grandiflora L. flower extract 


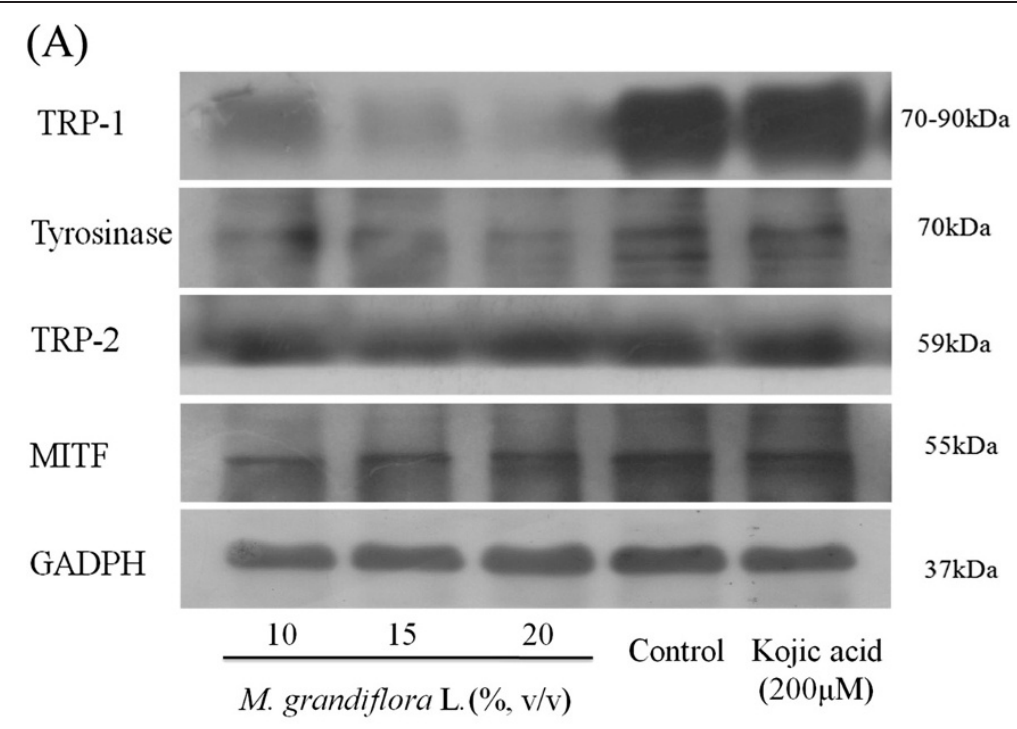

(B)

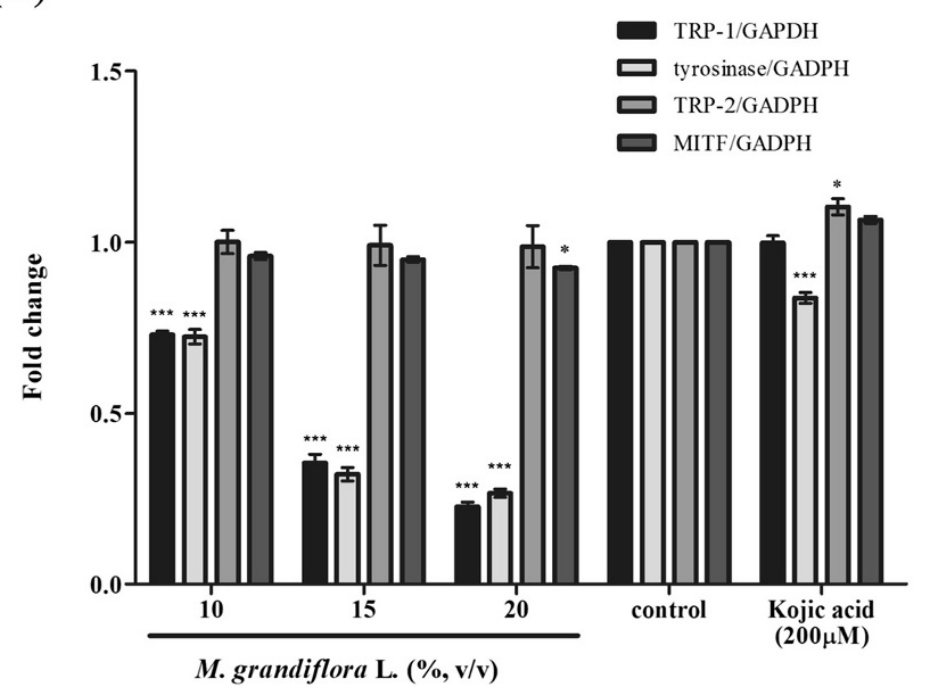

Figure 3 Effect of $\boldsymbol{M}$. grandiflora L. flower extract on melanogenesis-related proteins expression. (A) B16F10 cells were cultured with a-MSH (100 nM) for $24 \mathrm{~h}$ and then treated with various concentration of the flower extract (10, 15, 20\%; v/v) or kojic acid (200 $\mu$ M) for another 24 hr. Then the content of cellular MITF, tyrosinase, TRP-1 and TRP-2 proteins were analyzed by western blotting assay. (B) The relative amounts of MITF, tyrosinase, TRP-1 and TRP-2 compared to total GAPDH were calculated and analyzed by Multi Gauge 3.0 software and the values represented the mean of triplicate experiments \pm S.D.

was $57.50 \pm 0.40 \%, 63.52 \pm 0.39 \%, 70.92 \pm 0.43 \%$, respectively. The phenolic content of $20 \%(\mathrm{v} / \mathrm{v})$ of flower extract was similar to that of gallic acid (73.52 $\pm 0.19 \%)$.

To determine the reducing capacity of $M$. grandiflora L. flower extract, various concentrations of the flower extract $(10,15,20 \%, \mathrm{v} / \mathrm{v})$ or BHA $(0.05 \mathrm{mg} / \mathrm{ml})$ were tested. The results shown in Figure $4 \mathrm{C}$ revealed that higher concentrations of $M$. grandiflora L. flower extract present apparent reducing power. The reducing power of 10, 15, and 20\% (v/v) of M. grandiflora L. flower extract were $26.89 \pm 1.20 \%$, $32.20 \pm 0.48 \%$ and $36.47 \pm 1.08 \%$, respectively.

To confirm the antioxidant capacity of $M$. grandiflora L. flower extract in a cellular environment, evaluation of intracellular ROS levels was done. The concentration of $\mathrm{H}_{2} \mathrm{O}_{2}$ employed was $20 \mathrm{mM}$. After treatment, the remained intracellular ROS induced by $\mathrm{H}_{2} \mathrm{O}_{2}$ was $86.53 \pm 3.60 \%$ for $20 \%(\mathrm{v} / \mathrm{v})$ of the flower extract and $87.89 \pm 12.35 \%$ for Trolox (2.0 mM) (Figure 4D).

\section{Discussion}

Inhibition of melanogenesis effects of $M$. grandiflora L. flower extract

The MTT assay is a common colorimetric assay to measure the activity of enzymes that reduce MTT to formazan dyes, giving a purple color. It can also be used to determine the cytotoxicity of potential medicinal agents 
(A)

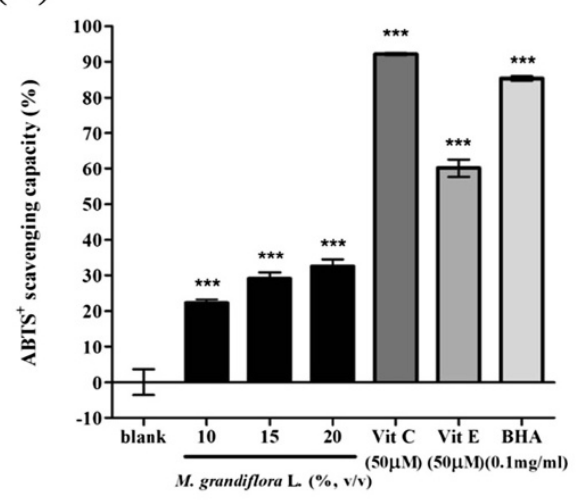

(C)

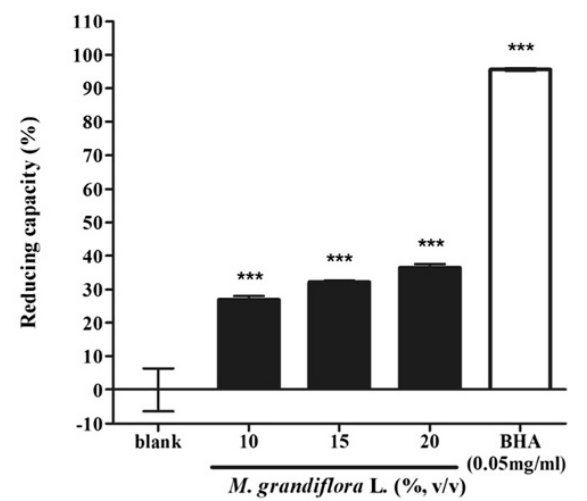

(B)

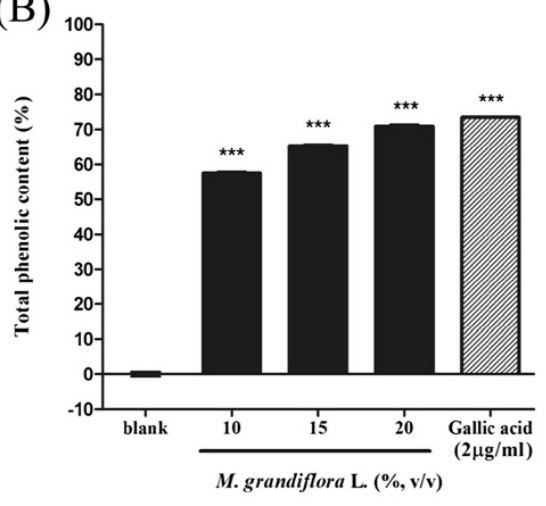

(D)

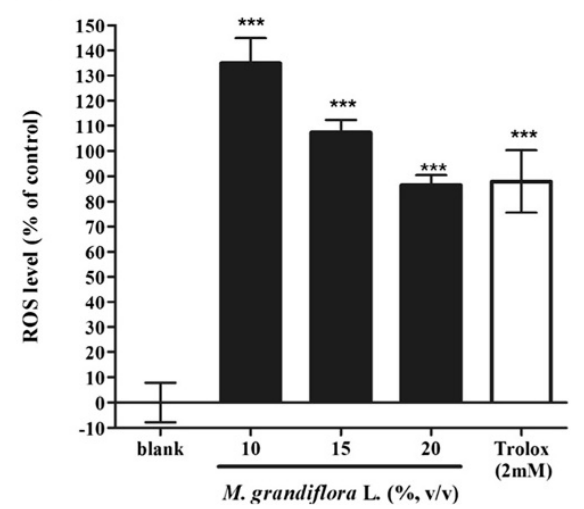

Figure 4 Antioxidant activities of $\boldsymbol{M}$. grandiflora L. flower extract. (A) ABTS ${ }^{+}$radical scavenging capacity assay. The flower extract $(10,15,20 \%$; $\mathrm{v} / \mathrm{V})$, vitamin $\mathrm{C}(50 \mu \mathrm{M})$, vitamin $\mathrm{E}(50 \mu \mathrm{M})$ or BHA $(0.1 \mathrm{mg} / \mathrm{ml})$ were incubated with $\mathrm{ABTS}^{+}$solution, respectively. (B) Determination of total phenolic content. Different concentrations of the $M$. grandiflora flower extract $(10,15,20 \%$; $v / v)$ and gallic acid $(2 \mu \mathrm{g} / \mathrm{ml})$ were used in the assay. (C) Reducing capacity assay. Different concentrations of the flower extract $(10,15,20 \%$; v/v) or BHA $(0.05 \mathrm{mg} / \mathrm{ml})$ were used in the test. (D) Determination of ROS content in B16F10 cells. Cells were treated with various concentrations of the flower extract (10, 15, 20\%; v/v) or Trolox (2.0 $\mathrm{mM}$ ) for $24 \mathrm{~h}$ and then the ROS content was measured by the DCF-DA assay. Results are represented as percentages of control, and the data are mean \pm S.D. for three separate experiments. Values are significantly different by comparison with control. ${ }^{* * *} p<0.001$.

and toxic materials, since those agents stimulate or inhibit cell viability and growth. The results shown in Figure 1 indicated that even higher concentration of $M$. grandiflora L. flower extract (20\%; v/v) also had no cytotoxic effect on B16F10 melanoma cell viability.

Tyrosinase plays an essential role in the first two steps of melanin synthesis pathway. It could convert L-tyrosine to L-DOPA and oxidizes L-DOPA to form dopachrome. Mushroom tyrosinase is widely used as the target enzyme in screening potential inhibitors of melanogenesis. The results shown in Figure 2A indicated that $M$. grandiflora L. flower extract show slightly lower inhibitory effect on mushroom tyrosinase activity than kojic acid does. To elucidate the true inhibitory effect of the flower extract on melanogenesis, B16F10 melanin content and intracellular tyrosinase activity were assayed at the same concentration range. The results shown in Figure 2B indicated that the flower extract from $M$. grandiflora L. present a stronger inhibitory effect on melanin formation in B16F10 cells than arbutin does. The data provided evidence that $M$. grandiflora L. flower extract blocks melanogenesis in B16F10 melanoma cells. The results shown in Figure $2 \mathrm{C}$ were in accordance with the results indicated in Figure 2B, which means the flower extract of $M$. grandiflora L. inhibited B16F10 intracellular tyrosinase activity and then decreased the melanin content in a dose-dependent manner. In the experiments, $\alpha-\mathrm{MSH}$ was used as a cAMP inducer to stimulate melanin synthesis. It is reported that $\alpha-\mathrm{MSH}$ can bind melanocortin 1 receptor (MC1R) and activate adenylate cyclase, which in turn catalyzes ATP to cAMP and increases intracellular cAMP level [22]. In the present study, the results show that $M$. grandiflora L. flower extract inhibited melanogenesis induced by $\alpha-\mathrm{MSH}$ mediated intracellular cAMP up-regulation.

TRP-1 and TRP-2 are two enzymes participated in regulation of tyrosinase activity. The results shown in Figure $3 \mathrm{~A}$ and $\mathrm{B}$ indicated that $M$. grandiflora L. flower 
extract decreased the protein expression levels of both tyrosinase and TRP-1, then inhibited tyrosinase activity and finally decreased melanin content in B16F10 cells. MITF is well known to act as a transcritption factor of tyrosinase. However, in our experiments, the flower extract did not affect MITF expression.

\section{Antioxidant capacities of $M$. grandiflora L. flower extract}

The $\mathrm{ABTS}^{+}$free radical has been widely used as a tool to estimate free radical scavenging activity of antioxidants. Antioxidants, on interaction with $\mathrm{ABTS}^{+}$, either transfer electrons or hydrogen atoms to $\mathrm{ABTS}^{+}$, thus neutralizing the free radical character [23]. In the present study, the flower extract showed lower free radical scavenging activities as compared to Vitamin C, Vitamin E or BHA.

When assay the total phenolic content of $M$. grandiflora L. flower extract, it was interesting to find that higher concentration of the flower extract $(20 \%, \mathrm{v} / \mathrm{v})$ has similar total phenolic content as gallic acid does. This is probably due to most bioactive compounds such as polyphenols including tannins and flavonoid existed in high polar extracts [24]. Polyphenols are one of the major plant compounds with antioxidant activity. The antioxidant activity of phenolic compounds is reported to be mainly due to their redox properties [25], which can play an important role in adsorbing and neutralizing free radicals, quenching singlet and triplet oxygen, or decomposing peroxides.

In the reducing power assay, it was found that the reducing power of the flower extract was much lower than that of BHA. Even though increases the concentration, the reducing power of the flower extract was still lower than that of BHA.

To confirm the antioxidant capacity of $M$. grandiflora L. flower extract in a cellular environment, evaluation of intracellular ROS levels was done. The principle of the assay is that DCFH-DA diffuses through the cell membrane and is enzymatically hydrolyzed by esterase to DCFH, which reacts with ROS (such as $\mathrm{H}_{2} \mathrm{O}_{2}$ ) to yield DCF. Rapid increases in DCF indicate oxidation of DCFH by intracellular radicals. The results revealed the flower extract depleted intracellular ROS in a dosedependent manner. The skin is exposed to UV and environmental oxidizing pollutants and is a preferred target of oxidative stress. It is reported that ultraviolet irradiation induce the formation of ROS in cutaneous tissue provoking toxic changes such as lipid peroxidation and enzyme inactivation [26]. To counteract the oxidative damage, skin is equipped with a network of enzymatic and nonenzymatic antioxidant systems.

It is reported that chronic exposure to solar UV radiation plays a role in the initiation of several skin disorders, including scaling, wrinkling, dryness and mottled pigment abnormalities such as hypopigmentation and hyperpigmentation $[27,28]$. Therefore, there is an increasing need for new and effective agents which perform photoprotection and skin whitening activities to prevent the above skin disorders. So far, there is no report about the effect of M. grandiflora L. flower extract on melanin production. This is the first study to evidence the potential inhibitory effect of $M$. grandiflora L. flower extract on melanogenesis in B16F10 melanoma cells. Besides, the flower extract also show antioxidant capacities, which fit the trend of skin whitening agents show dual functions including anitimelanogenenic and antioxidant activities. For example, several plants such as Paeonia suffruticosa [29] and chestnut flower extract [30] havd been reported to show antioxidant and antimelanogenic properties as M. grandiflora L. flower extract did. The present results suggested that $M$. grandiflora L. flower extract decreased melanin production may be attributed to inhibition of tyrosinase and TRP-1 or due to its depletion of cellular ROS.

\section{Conclusions}

In the study, M. grandiflora L. flower extract show potential dermatological effect against melanin production in B16F10 melanoma cells and present antioxidant capacities. This is the first report about the effect of $M$. grandiflora L. flower extract on melanin production. In the present study, it is found that M. grandiflora L. flower extract inhibit melanin synthesis significantly in a dose-dependent pattern. Besides, M. grandiflora L. flower extract also expressed antioxidant activities. The results suggested that $M$. grandiflora L. flower extract decreased melanin production may be attributed to its inhibitory action upon the signaling pathway regulating tyrosinase activity or depletion of cellular ROS. We will study the effects of various protein kinase inhibitors on melanogenesis in B16F10 melanoma cells after treatment with M. grandiflora L. flower extract in the near future. Certainly, we will also analyze the potential active components in the M. grandiflora L. flower extract and elucidate the possible whitening mechanisms.

\section{Methods}

\section{Chemicals and reagents}

Gallic acid, L-ascorbic acid (AA), Folin-Ciocalteau's phenol reagent, 1,1-diphenyl-2-picrylhydrazyl (DPPH), butylated hydroxyanisole (BHA) and all other chemicals and solvents were obtained from Sigma-Aldrich (St. Louis, MO).

\section{Preparation of $M$. grandiflora L. flower extract}

M. grandiflora L. fresh flowers $(2 \mathrm{~kg})$ were collected in May 2011 from a farm located at Jianshi township of Hsinchu county in Taiwan. The flowers were air-dried, crushed and added to $800 \mathrm{~mL}$ water at room temperature for $48 \mathrm{~h}$ to yield $650 \mathrm{~mL}$ aqueous extract. The final aqueous extract was stored at $4^{\circ} \mathrm{C}$ until use. 


\section{Cell culture}

B16F10 cells (ATCC CRL-6475; from the BCRC Cell Line Bank, BCRC60031) were cultured in DMEM with $10 \%$ fetal bovine serum (FBS; Gibco BRL, Gaithersburg, MD, USA) and penicillin/streptomycin (100 I.U/50 $\mu \mathrm{g} / \mathrm{mL})$ in a humidified atmosphere containing $5 \% \mathrm{CO}_{2}$ in air at $37^{\circ} \mathrm{C}$. All the experiments were performed in triplicate and were repeated 3 times to ensure reproducibility.

\section{Cell proliferation assay}

Cell viability assay of B16F10 was performed using 3-(4, 5-dimethylthiazol-2-yl)-2, 5-diphenyltetrazolium bromide (MTT) [31]. In brief, $1 \times 10^{4}$ cells/well was seeded into a 96-well plate. The cells were exposed to various concentrations of $M$. grandiflora L. flower extract (final concentration $10,12.5,15,17.5,20 \%$; v/v) for $24 \mathrm{~h}$, the MTT solution was added to the wells. The insoluble derivative of MTT produced by intracellular dehydrogenase was solubilized with ethanol-DMSO (1:1 mixture solution). The absorbance of the wells at $570 \mathrm{~nm}$ was read using a microplate reader.

\section{Assay of mushroom tyrosinase activity}

In order to assay the inhibitory action of $M$. grandiflora L. flower extract (final concentration 10, 15, 20\%; v/v) on mushroom tyrosinase, dose-dependent inhibition experiments were carried out in triplicate, as described previously, with a minor modification [32]. Briefly, $10 \mu \mathrm{L}$ of aqueous solution of mushroom tyrosinase (200 units) was added to a 96-well microplate, in a total volume of $200 \mu \mathrm{L}$ mixture containing $5 \mathrm{mM}$ L-DOPA which is dissolved in $50 \mathrm{mM}$ phosphate buffer $(\mathrm{pH}$ 6.8). The assay mixture was incubated at $37^{\circ} \mathrm{C}$ for $30 \mathrm{~min}$. Following incubation, the amount of dopachrome produced in the reaction mixture was determined spectrophotometrically at $490 \mathrm{~nm}\left(\mathrm{OD}_{490}\right)$ in a microplate reader. The inhibition percentage at three doses for each experiment was calculated by the following equation: inhibition percentage of tyrosinase activity $(\%)=(B-A) \div A \times 100$, where $B$ is the mean of the measured $\mathrm{OD}_{490}$ values of the blank control, and $\mathrm{A}$ is the mean of the measured $\mathrm{OD}_{490}$ values for the M. grandiflora L. flower extract treated group.

\section{Measurement of melanin content}

The intracellular melanin content was measured as described by Tsuboi et al [33] with some modifications. The cells were treated with $\alpha$-MSH (100 nM) for $24 \mathrm{~h}$, and then the melanin content was determined after treatment with either $M$. grandiflora L. flower extract (final concentration 10, 15, 20\%; v/v) or arbutin $(2.0 \mathrm{mM})$ for a further $24 \mathrm{~h}$. After treatment, the cells were detached by incubation in trypsin/ethylenediaminetetraacetic acid (EDTA). After precipitation, cell pellets containing a known number of cells were solubilized in $1 \mathrm{~N} \mathrm{NaOH}$ at $60^{\circ} \mathrm{C}$ for 60 min. The melanin content was assayed by spectrophotometric analysis at an absorbance of $405 \mathrm{~nm}$.

\section{Assay of B16F10 intracellular tyrosinase activity}

Cellular tyrosinase activity was determined as described previously [34] with slight modifications. Briefly, the cells were treated with $\alpha-\mathrm{MSH}(100 \mathrm{nM})$ for $24 \mathrm{~h}$, and then intracellular tyrosinase activity was measured after treatment with various concentrations of $M$. grandiflora L. flower extract (final concentration 10, 15, 20\%; v/v) or arbutin $(2.0 \mathrm{mM})$ for $24 \mathrm{~h}$. After these treatments, the cells were washed twice with phosphate-buffered saline and homogenized with $50 \mathrm{mM}$ PBS (pH 7.5) buffer containing $1.0 \%$ Triton X-100 and 0.1 mM PMSF. Intracellular tyrosinase activity was monitored as follows: Cell extracts $(100 \mu \mathrm{L})$ were mixed with freshly prepared L-DOPA solution $(0.1 \%$ in phosphate-buffered saline) and incubated at $37^{\circ} \mathrm{C}$. The absorbance at $490 \mathrm{~nm}$ was measured with microplate reader Gen $5^{\mathrm{TM}}$ (BIO-TEK Instrument, Bermont, USA) to monitor the production of dopachrome, corrected for auto-oxidation of L-DOPA.

\section{$\mathrm{ABTS}^{+}$scavenging capacity assay}

The ABTS decolorisation assays were carried out as previously described [35] and it involves the generation of ABTS + chromophore by oxidation of ABTS with potassium persulfate. The ABTS radical cation $\left(\mathrm{ABTS}^{+}\right)$was produced by reacting $7 \mathrm{mM}$ stock solution of ABTS with $2.45 \mathrm{mM}$ potassium persulfate and allowing the mixture to stand in the dark for at least $6 \mathrm{~h}$ before use. Absorbance at $734 \mathrm{~nm}$ was measured $10 \mathrm{~min}$ after mixing of different concentrations of the $M$. grandiflora L. flower extracts (final concentration 10, 15, $20 \%$; v/v) with $1 \mathrm{ml}$ of $\mathrm{ABTS}^{+}$solution. The ABTS scavenging capacity of the filtrate was compared with that of vitamin $C(50 \mu \mathrm{M})$ and vitamin $E(50 \mu \mathrm{M})$.

\section{Determination of total phenolic content}

The amount of total phenolics was determined with the Folin-Ciocalteu reagent [36]. First a standard curve was plotted using gallic acid as a standard. Different concentrations of samples were prepared in $80 \%$ of methanol. Hundred microliter of sample was dissolved in $500 \mu \mathrm{l}(1 /$ 10 dilution) of the Folin-Ciocalteu reagent and $1000 \mu \mathrm{l}$ of distilled water. The solutions were mixed and incubated at room temperature for $1 \mathrm{~min}$. After $1 \mathrm{~min}, 1500$ $\mu \mathrm{l}$ of $20 \%$ sodium carbonate solution was added. The final mixture was shaken and then incubated for $2 \mathrm{~h}$ in the dark at room temperature. The absorbance of samples was measuredat $760 \mathrm{~nm}$ and gallic acid $(2 \mu \mathrm{g} / \mathrm{ml})$ was used as standard.

\section{Determination of reducing capacity}

The reducing power of the extract was determined according to the method of Oyaizu [37]. Different 
concentrations of the flower extracts (final concentration $10,15,20 \% ; \mathrm{v} / \mathrm{v})$ or BHA $(0.05 \mathrm{mg} / \mathrm{ml})$ was mixed with phosphate buffer (2.5 ml, $0.2 \mathrm{M}, \mathrm{pH}$ 6.6) and potassium ferricyanide $\left[\mathrm{K}_{3} \mathrm{Fe}(\mathrm{CN})_{6}\right](2.5 \mathrm{ml}, 1 \% \mathrm{w} / \mathrm{v})$. The mixture was incubated at $50^{\circ} \mathrm{C}$ for $20 \mathrm{~min}$. A portion $(2.5 \mathrm{ml})$ of trichloroacetic acid $(10 \% \mathrm{w} / \mathrm{v})$ was added to the mixture, which was then centrifuged at $1000 \mathrm{~g}$ for $10 \mathrm{~min}$. The upper layer of solution $(2.5 \mathrm{ml})$ was mixed with distilled water $(2.5 \mathrm{ml})$ and $\mathrm{FeCl}_{3}(0.5 \mathrm{ml}, 0.1 \% \mathrm{w} / \mathrm{v})$, and the absorbance was measured at $700 \mathrm{~nm}$ in a UV-Vis spectrophotometer. Higher absorbance of the reaction mixture indicated greater reducing power.

\section{Cellular ROS level determination}

B16F10 melanoma cells were cultured in 24-well plates $\left(5 \times 10^{4}\right.$ cells in $1 \mathrm{~mL}$ of DMEM medium) and treated with various concentrations of $M$. grandiflora L. flower extract (final concentration 10, 15, 20\%; v/v) for $24 \mathrm{~h}$. The cells were then incubated with $24 \mathrm{mM} \mathrm{H}_{2} \mathrm{O}_{2}$ at $37^{\circ}$ $\mathrm{C}$ for $30 \mathrm{~min}$. After incubation, 2', 7'-dichlorofluorescein diacetate (DCFH-DA) was added to the wells, and the cells were cultured for $30 \mathrm{~min}$. After treatment, the cells were washed with phosphate-buffered saline, and trypsinized by trypsin/EDTA, and the fluorescence intensities of DCF were measured at excitation wavelength $504 \mathrm{~nm}$ and emission wavelength $524 \mathrm{~nm}$ using a fluorescent reader Fluoroskan Ascent (Thermo Scientific, Vantaa, Finland). The data were analyzed with Ascent software (Thermo Scientific, Vantaa, Finland). Cells with increased ROS content, appeared as a population with a higher fluorescence intensity [38].

\section{Western Blotting assay}

B16F10 cells, treated with $M$. grandiflora L. flower extract $(10,15,20 \% ; \mathrm{v} / \mathrm{v})$ or kojic acid $(200 \mu \mathrm{M})$, were washed twice with cold phosphate-buffered saline (PBS), lysed in PBS containing 1\% Nonidet P-40, 0.5\% sodium deoxycholate, $0.1 \%$ sodium dodecyl sulfate (SDS), $5 \mu \mathrm{g} / \mathrm{mL}$ of aprotinin, $100 \mu \mathrm{g} / \mathrm{mL}$ of phenylmethylsulfonyl fluoride, $1 \mu \mathrm{g} / \mathrm{mL}$ of pepstatin $\mathrm{A}$, and $1 \mathrm{mM}$ EDTA at $4^{\circ} \mathrm{C}$ for $20 \mathrm{~min}$, and then disrupted with a needle. Total cell lysates were quantified using a microBCA kit. Proteins $(50 \mu \mathrm{g})$ were resolved by SDS-polyacrylamide gel electrophoresis and electrophoretically transferred to a polyvinylidene fluoride (PVDF) filter. The nylon filter was blocked for $1 \mathrm{~h}$ in $5 \%$ fat-free milk in PBST buffer (PBS with 0. 05\% Tween-20). After a brief wash in the PBST buffer, the nylon filter was incubated overnight at $4^{\circ} \mathrm{C}$ with antibodies (antimicrophthalmia-associated transcription (MITF) antibody (1:1,000), anti-TRP1 antibody (1:2,000), anti-TRP2 antibody (1:2,000), anti-GAPDH antibody $(1: 3,000)$, and anti-tyrosinase antibody $(1: 2,000)$ (Epitomics, Burlingame, CA). Then the primary antibody was removed, and the filter was further washed extensively in PBST buffer. Subsequent incubation with goat anti-mouse antibody $(1: 10,000)$ conjugated with horseradish peroxidase was conducted at room temperature for $2 \mathrm{~h}$. The filter was washed extensively in PBST buffer to remove the secondary antibody, and the blot was visualized with ECL reagent. The relative amounts of MITF and tyrosinase, compared to total GAPDH were calculated and analyzed with Multi Gauge 3.0 software (Fuji, Tokyo).

\section{Statistical analysis}

Statistical analysis of the experimental data was performed by one-way ANOVA Tukey test, which was used for comparison of measured data using SPSS 12.0 statistical software (SPSS, Chicago). Differences were considered statistically significant at $p<0.05, * p<0.01$ and $* * * 0.001$.

\section{Competing interests}

All authors are in agreement with the content of the manuscript and the authors do not have any actual or potential conflict of interest, including any financial competing interests, non-financial competing interests, personal or other relationships with other people or organizations within that could inappropriately influence (bias) the work.

\section{Author details}

${ }^{1}$ Department of Medical Laboratory Science and Biotechnology, China Medical University, No. 91 Hsueh-Shih Road, Taichung, Taiwan 40402. 2Department of Applied Cosmetology \& Master Program of Cosmetic Science, Hung Kuang University, No. 34, Chung-Chie Rd., Shalu, Taichung City, Taiwan 43302. ${ }^{3}$ Niuer International Skincare Science Research Institute, 7F, No. 618, Ruiguang Rd., Neihu Dist., Taipei, Taiwan.

\section{Authors' contributions}

$\mathrm{H}-\mathrm{CH}$ carried out the tyrosinase-related studies, participated in the enzyme assays and drafted the manuscript. W-YH carried out antioxidant experiments. Y-LN carried out extraction of $M$. grandiflora $L$. fresh flowers and Western blot. T-MC participated in design and coordination of the study, performed the statistical analysis and drafted the manuscript. All authors read and approved the final manuscript.

\section{Authors' information}

1. Dr. Huey-Chun Huang is an associate professor in the department of Medical Laboratory Science and Biotechnology in China Medical University. 2. Miss Wan-Yu Hsie is a student in the master program of Cosmetic Science in Hung Kuang University.

3. Mr. Yu-Lin Niu is a lecturer in the department of Applied Cosmetology \& Master Program of Cosmetic Science in Hung Kuang University.

*Dr. Tsong-Min Chang is an associate professor in the department of Applied Cosmetology \& Master Program of Cosmetic Science in Hung Kuang University. He is also the chairman of the department of Applied Cosmetology and the director of Master Program of Cosmetic Science in Hung Kuang University.

Received: 24 February 2012 Accepted: 6 June 2012

Published: 6 June 2012

\section{References}

1. Briganti S, Camera E, Picardo M: Chemical and Instrumental Approaches to Treat Hyperpigmentation. Pigment Cell Res 2003, 16(2):101-110.

2. Seo S, Sharma V, Sharma N: Mushroom Tyrosinase: Recent Prospects. J Agric Food Chem 2003, 51(10):2837-2853.

3. Hearing $V$, Jimenez M: Mammalian tyrosinase-The critical regulatory control point in melanocyte pigmentation. Int J Biochem 1987, 19 (12):1141-1147.

4. Jimenez-Cervantes C, Solano F, Kobayashi T, Urabe K, Hearing VJ, Lozano JA, García-Borrón JC: A new enzymatic function in the melanogenic pathway. 
The 5,6-dihydroxyindole-2-carboxylic acid oxidase activity of tyrosinase-related protein-1 (TRP1). J Biol Chem 1994, 269(27):17993-18000.

5. Tsukamoto K, Jackson IJ, Urabe K, Montague PM, Hearing VJ: A second tyrosinase-related protein, TRP-2, is a melanogenic enzyme termed DOPAchrome tautomerase. EMBO J 1992, 11(2):519-526.

6. Funasaka Y, Komoto M, Ichihashi M: Depigmenting Effect of a-Tocopheryl Ferulate on Normal Human Melanocytes. Pigment Cell Res 2000, 13: 170-174.

7. Yamakoshi J, Otsuka F, Sano A, Tokutake S, Saito M, Kikuchi M, Kubota Y: Lightening Effect on Ultraviolet-Induced Pigmentation of Guinea Pig Skin by Oral Administration of a Proanthocyanidin-Rich Extract from Grape Seeds. Pigment Cell Res 2003, 16(6):629-638.

8. Imokawa G: Analysis of Initial Melanogenesis Including Tyrosinase Transfer and Melanosome Differentiation Though Interrupted Melanization by Glutathione. J Investig Dermatol 1989, 93(1):100-107.

9. Kumano $Y$, Sakamoto T, Egawa M, Iwai I, Tanaka M, Yamamoto I: In vitro and in vivo prolonged biological activities of novel vitamin $C$ derivative 2-O-alpha-D-glucopyranosyl-L-ascorbic acid (AA-2G), in cosmetic fields. J Nutr Sci Vitaminol 1998, 44(3):345-359.

10. Schühly W, Khan I, Fischer NH: The Ethnomedicinal Uses of Magnoliaceae from the Southeastern United States as Leads in Drug Discovery. Pharm Biol 2001, 39(s1):63-69.

11. Mellado V, Chavez SMA, Lozoya X: Pharmacological Screening of the aqueous extracts of Magnolia grandiflora L. Arch Med Res (Mex) 1980, 11 (3):335-346.

12. Bastidas Ramirez BE, Navarro Ruiz N, Quezada Arellano JD, Ruiz Madrigal B, Villanueeva Michel MT, Garzón P: Anticonvulsant effects of Magnolia grandiflora L. in the rat. J Ethnopharmacol 1998, 61(2):143-152.

13. Feraly El, Farouk S, Wen SL: Phenolic constituents of Magnolia grandiflora L. seeds. Lloydia 1977, 41

14. Rao KV, Davis TL: Constituents of Magnolia grandiflora I: Mono-O-Methylhonokiol. Planta Med 1982, 45(05):57-59.

15. Watanabe K, Watanabe H, Goto Y, Yamaguchi M, Yamamoto N, Hagino K Pharmacological Properties of Magnolol and Hōnokiol Extracted from Magnolia officinalis: Central Depressant Effects. Planta Med 1983, 49 (10):103-108.

16. Ikeda K, Nagase H: Magnolol Has the Ability to Induce Apoptosis in Tumor Cells. Biol Pharm Bull 2002, 25(12):1546-1549.

17. Clark AM, El-Feraly AS, Li W-S: Antimicrobial activity of phenolic constituents of magnolia grandiflora L. J Pharm Sci 1981, 70(8):951-952.

18. Feltenstein MW, Schühly W, Warnick JE, Fischer NH, Sufka KJ: Antiinflammatory and anti-hyperalgesic effects of sesquiterpene lactones from Magnolia and Bear's foot. Pharmacol Biochem Behav 2004, 79(2):299-302.

19. Koo TH, Lee J-H, Park YJ, Hong Y-S, Kim HS, Kim K-W, Lee JJ: A Sesquiterpene Lactone, Costunolide, from Magnolia grandiflora Inhibits NF-KB by Targeting IKB Phosphorylation. Planta Med 2001, 67(2):103-107.

20. Rao KV, Wu WN: Glycosides of Magnolia grandiflora. III: Structural elucidation of magnolenin C. J Nat Prod 1978, 41(1):56-62.

21. Rao KV, Davis TL: Constituents of Magnolia grandiflora, Cyclocolorenone. Planta Med 1982, 44(04):249-250.

22. Mukhtar H, Elmets CA: Photocarcinogenesis: Mechanisms, Models and Human Health Implications: Introduction. Photochem Photobiol 1996, 63 (4):356-357.

23. BuscÀ R, Ballotti R: Cyclic AMP a Key Messenger in the Regulation of Skin Pigmentation. Pigment Cell Res 2000, 13(2):60-69.

24. Banerjee A, Dasgupta N, De B: In vitro study of antioxidant activity of Syzygium cumini fruit. Food Chem 2005, 90(4):727-733.

25. Karmanoli K: Secondary metabolites as allelochemicals in plant defence against microorganisms of the phyllosphere. In Allelopathy from Molecules to Ecosystems. Edited by Reigosa M, Pedrol N. NH, USA: Science Publishers Inc; 2002.

26. Galato D, Ckless K, Susin MF, Giacomelli C, Ribeiro Do Vallle RM, Spinelli A: Antioxidant capacity of phenolic and related compounds: correlation among electrochemical, visible spectroscopy methods and structure antioxidant activity. Redox Rep 2001, 6(4):243-250.

27. Emerit I: Free radicals and aging of the skin. EXS 1992, 62:328-341.

28. Ding H-Y, Chou T-H, Lin R-J, Chan L-P, Wang G-H, Liang C-H: Antioxidant and antimelanogenic behaviors of Paeonia suffruticosa. Plant Foods Hum Nutr 2011, 66(3):275-284

29. Sapkota K, Park SE, Kim JE, Kim S, Choi HS, Chun HS, Kim SJ: Antioxidant and antimelanogenic properties of chestnut flower extract. Biosci Biotechnol Biochem 2010, 74(8):1527-1533.
30. Lister E, Wilson P: Measurement of Total Phenolics and ABTS Assay for Antioxidant Activity (Personal Communication). Lincoln, New Zealand: Crop Research Institute; 2001.

31. Oyaizu M: Studies on the products of browning reaction prepared from glucose amine. Jpn J Nutr 1986, 44:307-315.

32. Tada H, Shiho O, Kuroshima Ki, Koyama M, Tsukamoto K: An improved colorimetric assay for interleukin 2. J Immunol Methods 1986, 93(2): 157-165.

33. Bilodeau ML, Greulich JD, Hullinger RL, Bertolotto C, Ballotti R, Andrisani OM: BMP-2 Stimulates Tyrosinase Gene Expression and Melanogenesis in Differentiated Melanocytes. Pigment Cell Res 2001, 14(5):328-336.

34. Tsuboi T, Kondoh H, Hiratsuka J, Mishima Y: Enhanced melanogenesis induced by tyrosinase gene-transfer increases boron-uptake and killing effect of boron neutron capture therapy for amelanotic melanoma. Pigment Cell Res 1998, 11(5):275-282.

35. Jy Y, Koo Jh, Yg S, Kb K, Lee Jh, Hs S, Park Bh, Ec J, Jw P: Stimulation of melanogenesis by scoparone in B16 melanoma cells. Acta Pharmacol Sin 2006, 27(11):1467-1473.

36. Re R, Pellegrini N, Proteggente A, Pannala A, Yang M, Rice-Evans C Antioxidant activity applying an improved ABTS radical cation decolorization assay. Free Radic Biol Med 1999, 26(9-10):1231-1237.

37. Murrant $C L$, Reid $M B$ : Detection of reactive oxygen and reactive nitrogen species in skeletal muscle. Microsc Res Tech 2001, 55(4):236-248.

38. Ichihashi M, Ueda M, Budiyanto A, Bito T, Oka M, Fukunaga M, Tsuru K, Horikawa T: UV-induced skin damage. Toxicology 2003, 189(1-2):21-39.

doi:10.1186/1472-6882-12-72

Cite this article as: Huang et al:: Inhibition of melanogenesis and antioxidant properties of Magnolia grandiflora L. flower extract. BMC Complementary and Alternative Medicine 2012 12:72.

\section{Submit your next manuscript to BioMed Central and take full advantage of:}

- Convenient online submission

- Thorough peer review

- No space constraints or color figure charges

- Immediate publication on acceptance

- Inclusion in PubMed, CAS, Scopus and Google Scholar

- Research which is freely available for redistribution 